\title{
Pulmonary Function Test in Patients with Type 2 Diabetes Mellitus \& Its Correlation with Anthropometry and Glycemic Control
}

\author{
Ashok Kumar', Urvashi Khan², Shubha Laxmi Margekar ${ }^{3}$, Ashish Kumar Shukla ${ }^{4}$, Siva Prakash ${ }^{5}$ \\ ${ }^{1} \mathrm{MD}$ (Medicine), Professor \& Head, Department of Medicine, Santosh Medical College \& Hospitals, Ghaziabad, U.P, ${ }^{2}$ MBBS, Post Graduate Student, Department of \\ Medicine, Santosh Medical College \& Hospitals, Ghaziabad, U.P, ${ }^{3}$ Associate Professor Medicine, Lady Hardinge Medical College, New Delhi, ${ }^{4}$ Professor, \\ Department of Radiology, Santosh Medical College \& Hospitals, Ghaziabad, U.P, ${ }^{5}$ Post Graduate Student, Department of Medicine, Santosh Medical College \& \\ Hospitals, Ghaziabad, U.P.
}

\section{Abstract}

Background: Diabetes mellitus is a chronic disease with microvascular complications and affecting almost all organs in the body. Effect of diabetes on lung functions has been studied previously with variable results. This study was performed to see the lung functions in patients with type $2 \mathrm{DM}$ and to assess the pattern of abnormality in lung functions. Aim \& Objective: Our study aimed to evaluate pulmonary functions in patients with type 2 diabetes mellitus (T2DM) and to determine their correlations with anthropometric profile, glycaemic control, and diabetic microangiopathic complications. Subjects and Methods: 70 T2DM patients and 70 healthy control subjects were taken for the study. After taking an informed consent, all underwent screening with detailed history, anthropometry, blood sugar (fasting and post Prandial), glycosylated haemoglobin (HbA1C), renal profile, lipid profile and Pulmonary functions (spirometry). Statistical Analysis: Student's t-test was used to compare PFTs of diabetic and control groups. Frequencies were generated for categorical variables and compared using the chi square test. Results: There was significant reduction in all PFT parameters (PEFR (L/s), FEV1 \%, FVC ) in diabetics as compared to controls. The FEV1/FVC\% was higher in the diabetes group and there was a mixed restrictive and obstructive pattern of pulmonary dysfunction seen in diabetics.BMI was inversely related to PEFR, FEV1, and FVC. Age was inversely related to FEV1, and FVC. It was found that HbA1c was not significant for any ventilator (spirometric) index. Restrictive pattern rather than obstructive impairment of lung function is likely to be chronic complication of T2DM, the severity of which relates to longer duration of symptoms of diabetes, higher BMI, and advancing age. Conclusion: Spirometry is an easily available, non invasive screening tool to assess the lung functions and should be performed in patients with type 2 diabetes having microangiopathic complications.

Keywords: Diabetes Mellitus (DM), HbA1C, Pulmonary, Spirometry.

Corresponding Author: Dr. Ashok Kumar, Professor \& Head, Room No. 102, Department of Medicine, Santosh Medical College \& Hospitals, Ghaziabad, U. P (201001).

Email: drashish07@ rediffmail.com

Received: January 2020

Accepted: January 2020

\section{Introduction}

Diabetes mellitus is the most common metabolic disorder globally. It is accompanied by biochemical, morphological and functional abnormalities which may precipitate certain complications that affect neural, cardiovascular, renal systems, organs and tissues like skin, liver, collagen and elastic fibres. ${ }^{[1]}$ The metabolic disorder is a risk factor precipitating microvascular pathologies leading to autonomic neuropathy, nephropathy, retinopathy. Recently, the pulmonary function in diabetes has also become a subject of interest. ${ }^{[2-4]}$

Pulmonary dysfunction has been reported in patients with diabetes .The respiratory diseases associated with diabetes may result in changes in pulmonary volumes, diffusion and elastic properties of lungs as well as the performance of respiratory muscles. ${ }^{[5]}$ Ventilator function testing noninvasively quantifies physiological reserve in a large microvascular bed, and unlike myocardial and skeletal muscle function, pulmonary indices can be measured despite limitations in physical fitness and can, therefore, provide a useful measure of progression of diabetic microangiopathy. The lungs have been proposed as a target organ for diabetic microangiopathy in type 1 and type 2 diabetes. Our study was designed to compare the pulmonary function in diabetics with non diabetics.

\section{Subjects and Methods}

After informed consent of 140 patients of either sex attending/admitted to outpatient Department (OPD)/ ward at Department of Medicine, Santosh Medical College, Ghaziabad were enrolled for the study.

70 subjects with DMT2 (group A) who satisfied the inclusion criteria were recruited, and 70 healthy volunteers were recruited as controls (group B). Both groups were matched with regards to age, gender, height, BMI, and race (Indians). 
(1) Group A (n=70): DMT2 subjects.

Group A divided into 2 subgroups, namely group A1 and group A2;

Subgroup A1 ( $\mathrm{n}=54)$ : DMT2 subjects without any complications.

Subgroup A2 (n=16): DMT2 subjects with diabetic microvascular complications (retinopathy, nephropathy, and/or neuropathy).

(2) Group B (n=70): Control group of healthy non diabetic subjects.

\section{Inclusion criteria}

The study group included the ages between 30 to 60 years, who had never smoked and without any previous history of respiratory diseases or occupational exposure that could compromise lung function and clinically ruled out cardiovascular diseases.

\section{Exclusion criteria}

Patients with cardiovascular disease such as heart failure and those with physical disability capable of affecting lung function, such as kyphoscoliosis, pectus carinatum, and pectus excavatum, were excluded.

The protocol followed involved documentation of historical details, physical examination, anthropometric measurements, biochemical tests and PFT (spirometry) as mentioned below. In brief, the following parameters were measured.

\section{Anthropometric Measurements}

All patients were subjected to the following anthropometric measurements. 1. Height $(\mathrm{m}), 2$. Weight $(\mathrm{Kg}), 3$. Waist circumference (WC) $(\mathrm{cm}), 4$. Hip circumference $(\mathrm{HC})(\mathrm{cm})$, 5. BMI will be calculated from the height and weight (weight $/$ height $\left.^{2}\right)\left(\mathrm{Kg} / \mathrm{m}^{2}\right)$. 6. Waist Hip ratio (W-HR) was calculated from the mean of three readings of each $\mathrm{HC}$ and WC measurement.

\section{Biochemical Investigations}

Blood samples will be obtained after 12 hours overnight fast for estimation of levels of -

1. Blood Glucose (F and PP) 2.Lipid Profile 3.Glycosylated Haemoglobin $\left(\mathrm{HbA}_{1} \mathrm{c}\right)$ 4. Urine for microalbuminuria 5. Kidney function tests 6 . Haemogram. Glycosylated Haemoglobin (HbA1c) will be measured as an indicator of glycaemic control._Urine for microalbuminuria will be measured as an indicator of Diabetic Nephropathy. An oral glucose tolerance test was performed according to the world health organisation criteria.

\section{Pulmonary Function Test}

Chest $X$ Ray was done to exclude the presence of structurally obvious pulmonary disease. Pulmonary functions including- 1. Forced vital capacity (FVC), 2. Forced expired volume in one second $\left(\mathrm{FEV}_{1}\right), 3$. Peak expiratory flow rate (PEFR), 4. $\mathrm{FEV}_{1} / \mathrm{FVC}$.

These were measured by spirometer according to the American Thoracic Society criteria. ${ }^{[6]}$ Best of three satisfactory readings was taken for analysis. According to the GOLD (Global initiative for chronic obstructive lung disease), an obstructive ventilatory pattern was established by an $\mathrm{FEV}_{1}<80 \%$ of predicted, and $\mathrm{FEV}_{1} / \mathrm{FVC}<70 \%$ of predicted ( GOLD guideline criteria for stage 2). The definition of a restrictive lung disease was a FVC $<80 \%$ of predicted, with a $\mathrm{FEV}_{1} / \mathrm{FVC}$ ratio $>70 \%$ of predicted. ${ }^{[7]}$ All parameters were taken on spirometer (Medspiror D-0972509, from RMS recorders and medicare systems (P) (Ltd.)

\section{Statistical Analysis}

The results were analysed using Statistical Package for Social Sciences (SPSS) version 15.0. Mean, standard deviation and range were computed for all quantitative variables and comparison was done using Independent/Unpaired Student's t-test. Frequencies were generated for categorical variables and compared using the chi square test. Multiple linear regression analysis was utilized for the assessing the impact of variables on the ventilatory function; $\mathrm{p}<0.05$ was accepted as significant and $<0.001$ were deemed highly significant.

\section{Results}

A total of 140 subjects were studied. The diabetes group (group A) comprised 70 subjects, while the control subjects (group B) comprised 70 subjects without diabetes.

Demographic and anthropometric data for the diabetes subjects and controls are summarised in Table 1 and show no significant difference in age distribution, gender, height, and BMI ( $p>0.05$ in all cases).

For the diabetes subjects, the mean HbA1c was $8.75 \pm 2.53$ $\%$, which was significantly higher than group B $(\mathrm{p}<0.01)$ and $41.6 \%$ of them had HbA1c levels less than $7 \%$, indicating good glycemic control. The duration of diabetes ranged from 1 year to 18 years.

\section{Ventilatory indices}

Table 2 is a comparison of the ventilatory indices in the study group and control group and it shows that the FEV1, and FVC were significantly lower in the diabetes subjects compared with the control subjects $(p=0.01,0.01$, respectively); and PEFR also show a reduced trend though not significant, $(\mathrm{p}=0.08)$ but the $\mathrm{FEV} 1 / \mathrm{FVC} \%$ was not significant $(p=0.243)$. Eight $(11 \%)$ of the subjects with type 2 diabetes had restrictive lung disease and $4(6 \%)$ had obstructive lung disease, while $1(1 \%)$ of controls had restrictive lung disease and $3(5 \%)$ had obstructive lung disease $\left(x^{2}=9.46, p=0.009\right)$. This is shown in Table 3 .

Out of 12 (17\%) of study subjects (group A) with abnormal spirometry function; 9 (13\%) subjects were from subgroup A2 and only $3(4 \%)$ subjects were from subgroup A1. This shows a increased frequency of abnormalities on spirometry in subgroup A2; supporting the concept of the lung as one of the target organ of diabetic microangiopathy.

\section{Determinants of ventilatory indices}

Multiple linear regression analysis was utilised for the determinants of ventilatory indices in the diabetes subjects. 
The model included the following variables: HbA1c (\%), duration of symptoms of diabetes (years), age (years), BMI $\left(\mathrm{kg} / \mathrm{m}^{2}\right)$, waist circumference $(\mathrm{cm})$. BMI was significantly and inversely related to the PEFR, FEV1, and FVC ( $p=0.01$, $0.006,0.018$, respectively). Duration of diabetes was significantly and inversely related to the FEV1, and FVC $(p=0.001,0.001$, respectively). Age was significantly and inversely related to the $\mathrm{FEV}_{1}$, and $\mathrm{FVC}(p=0.01,0.004$, respectively).

Table 4 shows a comparison of mean $\pm \mathrm{SD}$ of anthropometric parameters (WC, HC, WH-R, BMI), age, $\mathrm{HbA}_{1} \mathrm{c}$, and duration of diabetes, between group $\mathrm{A}$ (diabetic subjects) with normal ventilatory function and those with abnormal ventilatory function. The mean $\pm \mathrm{SD}$ of age, WC, and WH-R were the only variables significantly higher in those diabetes subjects with abnormal ventilatory function compared with normal ventilatory function, irrespective of restrictive or obstructive patterns $(\mathrm{p}=0.002,0.03,0.04$ respectively).

Table 1: Demographic and anthropometric values for the T2DM subjects and controls

\begin{tabular}{|c|c|c|c|c|c|}
\hline Parameter & \multicolumn{2}{|c|}{ Diabetes $\mathbf{n}=\mathbf{3 0}$} & \multicolumn{2}{|c|}{ Control $n=50$} & p value \\
\hline & Range & Mean -+SD & Range & $\begin{array}{l}\text { Mean- } \\
+ \text { SD }\end{array}$ & $S<0.05$ \\
\hline Age (yrs.) & $30-59$ & $46.08-+7.62$ & $30-60$ & $\begin{array}{l}45.67- \\
+7.94\end{array}$ & 0.75 \\
\hline Gender & & $\mathrm{F}=52.8 \%(37)$ & & $\begin{array}{l}F=51.4 \% \\
(36)\end{array}$ & 0.86 \\
\hline Height (m) & $\begin{array}{l}1.19- \\
1.98\end{array}$ & $1.65 \pm 0.08$ & $\begin{array}{l}1.45- \\
1.93\end{array}$ & $\begin{array}{l}1.65 \\
\pm 0.06\end{array}$ & 0.62 \\
\hline $\begin{array}{l}\text { BMI } \\
\left(\mathrm{kg} / \mathrm{m}^{2}\right)\end{array}$ & $\begin{array}{l}19.94- \\
39.63\end{array}$ & $29.05 \pm 3.78$ & $\begin{array}{l}19.12 \\
-39\end{array}$ & $\begin{array}{l}28.41 \\
\pm 3.90\end{array}$ & 0.32 \\
\hline $\mathrm{WC}(\mathrm{cm})$ & $\begin{array}{l}75- \\
119\end{array}$ & $93.97 \pm 10.55$ & $\begin{array}{l}75- \\
121\end{array}$ & $\begin{array}{l}92.42 \\
\pm 10.37\end{array}$ & 0.38 \\
\hline
\end{tabular}

BMI: Body mass index; WC: Waist Circumference

\begin{tabular}{|l|l|l|l|}
\hline Table 2: Mean ventilator indices in T2DM and control subjects \\
\hline Parameter & $\begin{array}{l}\text { Diabetes } \\
\text { subjects, } \\
\text { Group A } \\
\text { n= 70 }\end{array}$ & $\begin{array}{l}\text { Controls, } \\
\text { Group B } \\
\text { n= 70 }\end{array}$ & p value \\
\hline & Mean \pm SD & Mean \pm SD & $\mathrm{S} \leq 0.05$ \\
\hline PEFR (L/s) & $5.77 \pm 1.78$ & $6.20 \pm 1.08$ & 0.08 \\
\hline $\mathrm{FEV}_{1}(\mathrm{~L})$ & $2.14 \pm 0.61$ & $2.63 \pm 0.41$ & 0.01 \\
\hline $\mathrm{FVC} \mathrm{L})$ & $2.57 \pm 0.78$ & $3.16 \pm 0.46$ & 0.01 \\
\hline $\mathrm{FEV}_{1} / \mathrm{FVC}$ & $83.82 \pm 18.50$ & $81.15 \pm 4.52$ & 0.24 \\
\hline
\end{tabular}

PEFR: Peak expiratory flow rate, $\mathrm{FEV}_{1}$ : Forced expired volume in one second, FVC : Forced Vital capacity

Table 3: Abnormal Spirometry in the diabetes group and control group

\begin{tabular}{|l|l|l|}
\hline & $\begin{array}{l}\text { Cases } \\
\text { (Group A ) }\end{array}$ & Controls(Group B ) \\
\hline Abnormal spirometry function & $12(17 \%)$ & $4(6 \%)$ \\
\hline Restrictive spirometry defect & $8(11 \%)$ & $1(1 \%)$ \\
\hline Obstructive spirometry defect & $4(6 \%)$ & $3(5 \%)$ \\
& & \\
\hline
\end{tabular}

\section{Discussion}

Diabetes is a multisystemic disease and microangiopathy affects almost every organ. The effects of diabetes on the ventilatory function (spirometry) and to determine various correlations between ventilatory function (spirometry) with anthropometric profile, glycaemic control and microangiopathic complications; is the focus of this study.

The results were obtained in each groups and subsequently compared with the control group (group B) and other group of patients (group A, subgroups A1, A2).

Table 4: Mean values $( \pm$ SD) of anthropometric data, historical data, and HbA1c levels of study group (group A) with normal and abnormal ventilatory function

\begin{tabular}{|c|c|c|c|c|}
\hline & $\begin{array}{l}\text { Group A } \\
\text { with } \\
\text { Normal } \\
\text { ventilatory } \\
\text { function } \\
\mathrm{n}=\mathbf{5 8} \\
(\mathbf{8 3 \%}) \\
\end{array}$ & $\begin{array}{l}\text { Group A } \\
\text { with } \\
\text { Abnormal } \\
\text { ventilatory } \\
\text { function } \\
\mathrm{n}=12 \\
(\mathbf{1 7 \%})\end{array}$ & t- value & p-value \\
\hline $\mathrm{HbA}_{1} \mathbf{c}(\%)$ & $8.5 \pm 2.67$ & $8.75 \pm 1.82$ & 0.98 & 0.50 \\
\hline Age (Yrs.) & $44.84 \pm 7.42$ & $52.08 \pm 5.83$ & 3.17 & 0.002 \\
\hline $\operatorname{BMI}\left(\mathrm{Kg} / \mathbf{m}^{2}\right)$ & $28.88 \pm 3.91$ & $29.89 \pm 3.05$ & 0.83 & 0.40 \\
\hline WC (cm) & $\begin{array}{l}92.79 \\
\pm 10.48\end{array}$ & $99.66 \pm 9.30$ & 2.10 & 0.03 \\
\hline HC (cm) & $94.93 \pm 5.83$ & $94.83 \pm 6.39$ & 0.05 & 0.95 \\
\hline WH-R & $0.98 \pm 0.11$ & $1.05 \pm 0.10$ & 2 & 0.04 \\
\hline $\begin{array}{l}\text { Duration of } \\
\text { diabetes (Yrs.) }\end{array}$ & $5.97 \pm 3.89$ & $7.25 \pm 5.21$ & 0.97 & 0.334 \\
\hline
\end{tabular}

The mean age \pm SD in subjects of group A was 46.08 \pm 7.65 years and in group B was $45.67 \pm 7.94$ years (table 1); both the groups (group A and group B) were matched for age, so as to nullify the effect of age on the study. There was no significant difference in the age distribution among the study group (group A) and the control group (group B).

The gender distribution in our study is presented in table 1 . There were 67 males and 73 females were in both the groups (group A and B). Both groups were matched for gender, so as to nullify the effect of gender distribution on the study.

The duration of diabetes among subgroups A1 and A2 was compared. The duration of diabetes among subjects of group A ranged from 1 year to 17 years. The duration of diabetes among subjects of subgroup A2 was $10 \pm 4.93$ years, $\mathrm{p}<0.05$; was significantly higher than that of subgroup A1 which was $4 \pm 3.38$ years.

The biochemical profile of both groups was compared. There was a significant higher levels of blood sugar levels [fasting $(178 \pm 16.94 \mathrm{mg} / \mathrm{dl})$ and post Prandial $(246 \pm 25 \mathrm{mg} / \mathrm{dl})]$, glycated haemoglobin levels $(8.75$ $\pm 2.53 \%)$, triglycerides levels $(199 \pm 104.02 \mathrm{mg} / \mathrm{dl})$; noted among diabetics ( $\mathrm{p}<0.001$ respectively) as compared of controls .In our study, diabetic patients had significant hypertriglyceridaemia as compared to controls. This finding has been observed in other studies too like, Sinha et al.(2004) in their study 
showed a significant correlation between decreased DLCO and cholesterol levels in diabetic subjects. ${ }^{[8]}$

The pulmonary function profiles of both groups (group A and group B) are presented in table 3. On spirometry, diabetic patients showed a significant reduction in $\mathrm{FEV}_{1}$ and $\mathrm{FVC}(\mathrm{p}=0.01, \quad 0.01$ respectively), relative to non-diabetic controls (group B). There was no significant difference noted in the forced expiratory ratio $\left(\mathrm{FEV}_{1} / \mathrm{FVC}\right)$ between the groups (table 6). Thus, the main finding in our study is that, ventilatory function $\left(\mathrm{FEV}_{1}\right.$ and $\left.\mathrm{FVC}\right)$ is significantly reduced in diabetes subjects compared with controls without diabetes; our finding are supported by Asanuma Y et al.(1985), they reported that FVC and $\mathrm{FEV}_{1}$ were reduced in Japanese diabetic subjects compared to control subjects without diabetes. ${ }^{\left[{ }^{9]}\right.}$ Meo et al.(2005, 2006), in their studies on Saudi diabetic patients showed significant reduction in FVC , $\mathrm{FEV}_{1}$ and PEF (Peak Expiratory Flow Rate) as compared to their matched controls. ${ }^{[10,11]}$

Davis et al.(2000), conducted a large community-based study in Western Australia on type-2 diabetic patients and demonstrated that $\mathrm{VC}, \mathrm{FVC}, \mathrm{FEV}_{1}$ and PEF were decreased in type- 2 diabetic patients. They also suggested that the reduced lung volumes and air flow limitations are likely to be chronic complication of type-2 diabetes. ${ }^{[5]}$

The proportion of diabetic subjects with obstructive lung disease was similar to the proportion in controls (6\% among group A and 5\% among group B), suggesting that this defect is not necessarily due to diabetes. Also, the proportion of diabetic subjects with microangiopathies (i.e subgroup A2) had more frequency of ventilatory dysfunction (predominantly restrictive defect) among them; (out of 12 subjects with abnormal ventilatory function among diabetic subjects, 9 subjects were from subgroup A2 and 3 subjects were from group A1) as shown in Table 3.

Our finding of predominantly restrictive lung defect in type 2 diabetes, that too more frequently in type 2 diabetes subjects with microangiopathies; is supported by studies of lung function in diabetes in which carbon monoxide diffusing capacity (DLco) was also measured and found to be significantly lower than that of controls. ${ }^{[8,12,13]}$

The functional abnormalities ensuing from these changes manifest clinically by way of a reduction in elastic recoil of the lung, lung volumes and pulmonary capacity for the diffusion of carbon monoxide. ${ }^{[14]}$ The concomitant pulmonary structural impact of these biochemical alterations, described to date, consist of a thickening of the alveolar epithelial basal lamina. ${ }^{[15]}$ and a specific type of nodular fibrosis of the lung. ${ }^{[16]}$

\section{Sub Group Analysis}

Determinants of Ventilatory indices among diabetics (Group A)

In addition, we evaluated some possible determinants of ventilatory defect in diabetic patients (group A) and found age, BMI, and the duration of diabetes to be the significant determinants with an inverse relationship to the ventilatory indices (spirometry).

The duration of diabetes was a significant determinant of FEV1 and FVC. This agrees with the findings in earlier population-based studies in Australia, Denmark, and India.$^{[5,8,17]}$.The BMI had a significant inverse relationship to the PEFR, FEV1, and FVC in this study. The Fremantle Diabetes Study (FDS, 2000), a population-based study in southern Australia also found that BMI, coronary artery disease, and age were significant determinants of ventilatory function. ${ }^{[5]}$ The effect of BMI in reducing lung function has been well documented by various studies ${ }^{[18-21]}$.Factors responsible for this include, reduced chest wall compliance and increased airway resistance.

The waist circumference and waist hip ratio (WH-R) of the diabetic subjects (group A) with abnormal ventilatory defects was significantly higher than the WC and WH-R of the diabetic subjects with normal ventilatory function; in this study, as shown in table 4; this finding suggests that increased waist circumference (truncal obesity) may aggravate the decline in ventilatory function. This is thought to be due to limited ability of the diaphragm to displace abdominal fat as well as the role of waist circumference in the metabolic syndrome. Similar findings have been suggested by previous studies. ${ }^{[18,20,21]}$

The age of the subjects in group A (diabetics) with ventilatory defects was significantly higher than the age of the diabetic subjects with normal ventilatory function, as shown in table 4; this reflects the expected age-related decline in lung function. ${ }^{[22,23]}$

Glycated Haemoglobin levels was not a significant determinant of ventilatory function in multivariate analysis in this study and this finding is supported by previous studies. ${ }^{[5,13]}$ This is reasonable because the HbA1c levels reflects only the glycaemic control in the previous 2 to 3 months, a duration which may not be long enough to impart an effect on lung function. However long-term glycaemic control, which is determined as the mean updated HbAlc over many years and referred to as glycaemic exposure has been found to be a major determinant of lung function. ${ }^{[24]}$

\section{Conclusion}

Abnormality in pulmonary functions are common in type 2 DM Patients which may go unrecognised if not evaluated properly. In diabetic patients with microangiopathic complications restrictive pattern of spirometric abnormalities are common, the severity of which relates to longer duration of symptoms of diabetes and higher body mass index. Pulmonary function test (spiromerty) is a very effective non invasive screening tool to assess the abnormalities in lung functions and should be performed in 
type2 DM to prevent complications as lungs are affected in patients to improve the quality of life.

Further studies are needed to define not only the mechanism involved in the pulmonary dysfunction associated with T2DM , but also to determine whether blood glucose control could prevent lung injury.

\section{References}

1. Nathan DM . Long-term complications of diabetes mellitus . N Engl J Med . 1993 ; 328 ( 23 ): 1676 - 1685

2. Kuitert LM. The lung in diabetes-yet another target organ? Chron Respir Dis . 2008 ; 5 ( 2 ): 67 - 68 .

3. Hsia CC , Raskin P. Lung involvement in diabetes: does it matter? Diabetes Care . 2008 ; 31 ( 4 ): 828 - 829.

4. Teeter JG, Riese RJ. Cross-sectional and prospective study of lung function in adults with type 2 diabetes: the Atherosclerosis Risk in Communities (ARIC) study: response to Yeh et al . Diabetes Care . $2008 ; 31$ ( 10 ): e82 .

5. Davis TME, Knuiman M, Kendall P, Vu H, Davis WA: Reduced pulmonary function and its associations in type 2 diabetes: the Fremantle Diabetes Study. Diabetes Res Clin Pract 50:153-159, 2000.

6. Ljubic S, Metelko Z, Car N, Roglic G, Drazic Z. Reduction of diffusion capacity for carbon monoxide in diabetic patients. Chest 1998; 114 : 1033-5.

7. Global Initiative for Chronic Obstructive Lung Disease. Global strategy for the diagnosis, management, and prevention of chronic obstructive pulmonary disease. (Updated 2007). http://www.goldcopd.org.

8. Sinha S, Guleria R, Pandey RM, Tiwari S. Pulmonary functions in patients with type 2 diabetes mellitus and correlation with anthropometry and microvascular complications. Indian J Med Res 2004, 119: 66-71.

9. Asanuma Y, Fujiya $\mathrm{S}$, Ide $\mathrm{H}$ et al. Characteristics of pulmonary function in patients with diabetes mellitus. Diabetes Res Clin Pract 1985;37:829-831

10. Meo SA, Al-Drees AM, Arif M, Al-Rubean K. Lung function in type 1 Saudi diabetic patients. Saudi Med J 2005; 26: 1728-33.
11. Meo SA, Al-Drees AM, Arif M, Al-Rubean K. Lung function in type 2 Saudi diabetic patients. Saudi Med J 2006; 27: 338-43.

12. Schuytler M, Niewoehner D, Inkley S, Kohn R: Abnormal lung elasticity in juvenile diabetes mellitus. Am Rev Resp Dis 1976, 113:37-41.

13. Sandler M, Burn A, Stewart R. Cross-sectional study of pulmonary function in patients with insulin dependent diabetes mellitus. Am Rev Respir Dis 1987; 135: 223-228.

14. Weir DC, Jennings PE, Hendy MS, Barnett AH, Burge PS. Transfer factor for carbon monoxide in patients with diabetes with and without microangiopathy. Thorax 1988;43:725-6.

15. Vracko R, Thorning D, Huang TW. Basal lamina of alveolar epithelium and capillaries: quantitative changes with aging and in diabetes mellitus. Am Rev Respir Dis 1979; 120: 973-983.

16. Farina J, Furio V, Fernandez-Acenero MJ, Muzas MA. Nodular fibrosis of the lung in diabetes mellitus. Virchows Arch 1995; 427: 61-63.

17. Lange P, Parner J, Schnohr P, Jensen G. Copenhagen City Heart Study: longitudinal analysis of ventilator capacity in diabetic and non-diabetic adults. Eur Respir J 2002; 20: 1406-1412.

18. Canory D, Luben R, Welch A, et al. Abdominal obesity and respiratory function in men and women in the EPIC-Norfolk study United Kingdom. Am J Epidemiol 2004; 159 (Suppl 12): 1140-9.

19. Ochs-Balcom HM, Grant BJ, et al. Pulmonary function and abdominal obesity in the general population. Chest 2006; 129 (suppl 4): 853-62.

20. Wen-Yuan L, Chien-An Y, Hao-Chien W, Kuo-Chin H. Impaired lung function is associated with obesity and metabolic syndrome in adults. Obesity 2006; 14: 1654-61.

21. Li AM, Chan. The effect of obesity on pulmonary function. Arch Dis Child 2003; 88: 361-3.

22. Ele PU. Reference values for FEV1 and FVC in male adolescents and young adults of Ibo origin. East Afr Med J 1992; 69: 105-9.

23. Schoenberg JB, Beck GJ, Boubuys. Growth and decay of pulmonary function in healthy blacks and whites. Resp Physical 1978; 33: 36793

24. Davis WA, Knuiman M, Kendell P, Grange V, Davis TME. Glycemic exposure is associated with reduced pulmonary function in type 2 diabetes: The Fremantle Diabetes Study. Diabetes Care 2004; 27: $752-7$.

Copyright: () the author(s), 2020. It is an open-access article distributed under the terms of the Creative Commons Attribution License (CC BY 4.0), which permits authors to retain ownership of the copyright for their content, and allow anyone to download, reuse, reprint, modify, distribute and/or copy the content as long as the original authors and source are cited.

How to cite this article: Kumar A, Khan U, Margekar SL, Shukla AK, Prakash S. Pulmonary Function Test in Patients with Type 2 Diabetes Mellitus \& Its Correlation with Anthropometry and Glycemic Control. Asian J. Med. Res. 2020;9(1):ME01-ME05.

DOI: dx.doi.org/10.47009/ajmr.2020.9.1.ME1 